\title{
Penentuan Energi Osilator Kuantum Anharmonik Menggunakan Teori Gangguan
}

\author{
Iklas Sanubary11, Yudha Arman'1), Azrul Azwar'1) \\ 1)Program Studi Fisika \\ Fakultas Matematika dan Ilmu Pengetahuan Alam \\ Universitas Tanjungpura \\ Email : iklassanubary16@gmail.com
}

\begin{abstract}
Abstrak
Persamaan Schrödinger untuk osilator kuantum anharmonik tidak bisa diselesaikan secara analitik, sehingga diperlukan metode lain untuk menentukan energi osilator kuantum anharmonik. Metode yang dapat digunakan adalah teori gangguan. Pada penelitian ini teori gangguan digunakan untuk menentukan tingkat energi osilator kuantum anharmonik untuk beberapa suku gangguan yang tunggal dan suku gangguan dalam bentuk polinomial. Hasil penelitian menunjukkan bahwa perubahan tingkat-tingkat energi akibat suku gangguan dalam bentuk polinomial merupakan penjumlahan dari beberapa suku gangguan yang tunggal.
\end{abstract}

Kata kunci: osilator anharmonik, persamaan Schrödinger, teori gangguan

\section{Pendahuluan}

Persamaan Schrödinger memainkan peranan penting dalam mekanika kuantum sebagaimana persamaan gerak Newton dalam mekanika klasik (Beiser, 1987). Penyelesaian persamaan tersebut akan memberikan informasi mengenai karakteristik partikel.

Untuk menyelesaikan persamaan Schrödinger, meskipun dalam bentuk yang relatif sederhana, yaitu bentuk yang tidak bergantung waktu, memerlukan perhitungan matematis yang rumit. Salah satu contohnya adalah osilator kuantum anharmonik. Solusi dari persamaan tersebut tidak dapat diselesaikan secara analitik (Jafarpour dan Afshar, 2001).

Metode yang dapat digunakan untuk mendapatkan solusi dari osilator kuantum anharmonik adalah teori gangguan (Tjia, 1999). Metode ini didasarkan pada penyederhanaan suatu sistem kuantum yang rumit menjadi lebih sederhana sehingga solusi aproksimasi dapat diperoleh (Griffiths, 1995). Teori gangguan digunakan untuk memperkirakan perubahan tingkat-tingkat energi dan fungsi gelombang yang yang disebabkan oleh adanya suku gangguan (Ohno, 2009).

Pada penelitian ini teori gangguan digunakan untuk menentukan tingkat energi osilator kuantum anharmonik untuk beberapa suku gangguan yang tunggal dan suku gangguan dalam bentuk polinomial. Perubahan tingkat energi akibat kedua bentuk suku gangguan ini akan dibandingkan, kemudian pengaruh bentuk suku gangguan terhadap perubahan tingkattingkat energi akan dianalisis.

\section{Landasan Teori}

Hamiltonian sistem osilator kuantum anharmonik dengan suku gangguan $\lambda x^{m}$ dapat dituliskan dalam bentuk

$$
H=-\frac{\hbar^{2}}{2 m} \frac{d^{2}}{d x^{2}}+\frac{1}{2} k x^{2}+\lambda x^{m}
$$

Sedangkan Hamiltonian sistem osilator kuantum anharmonik dengan suku gangguan dalam bentuk polinomial dapat dituliskan sebagai berikut

$$
H=-\frac{h^{2}}{2 m} \frac{d^{2}}{d x^{2}}+\frac{1}{2} k x^{2}+\sum_{m=0}^{m} \lambda_{m} x_{m}
$$

dengan $\lambda$ merupakan suatu konstanta dan $m$ merupakan bilangan cacah, $m=0,1,2,3 \ldots$.

Hamiltonian sistem dalam teori gangguan diuraikan menjadi dua bagian utama, yaitu Hamiltonian tanpa gangguan dan Hamiltonian dengan gangguan (Purwanto, 2006). Secara umum dapat dituliskan sebagai:

$$
H=H_{0}+\lambda H_{1}
$$

dengan $H_{0}$ merupakan Hamiltonian tanpa gangguan dan $\lambda H_{1}$ merupakan Hamiltonian dengan gangguan.

Akibat gangguan tersebut, nilai dan fungsi eigen energi akan mengalami koreksi kecil (Zen dan Suroso, 2011)

$$
E_{n}=E_{n}^{(0)}+\Delta E_{n}
$$




$$
\psi_{n}=\psi_{n}^{(0)}+\Delta \psi_{n}
$$

Nilai dan fungsi eigen energi dapat dituliskan dalam bentuk sebuah deret pangkat pada $\lambda$ (Floyd dkk, 2011)

$$
\begin{gathered}
E_{n}=E_{n}^{(0)}+\lambda E_{n}^{(1)}+\lambda^{2} E_{n}^{(2)}+\ldots \\
\psi_{n}=\psi_{n}^{(0)}+\lambda \psi_{n}^{(1)}+\lambda^{2} \psi_{n}^{(2)}+\ldots
\end{gathered}
$$

dengan $E_{n}^{(1)}$ dan $E_{n}^{(2)}$ merupakan koreksi energi orde pertama dan kedua dari nilai eigen serta $\psi_{n}^{(1)}$ dan $\psi_{n}^{(2)}$ merupakan koreksi orde pertama dan kedua dari fungsi eigen.
Energi koreksi orde pertama diberikan oleh persamaan

$$
E_{n}^{(1)}=\left\langle n\left|H_{1}\right| n\right\rangle
$$

dan untuk energi koreksi orde kedua diberikan oleh persamaan

$$
E_{n}^{(2)}=\sum_{r \neq n} \frac{\left|\left\langle n\left|H_{1}\right| r\right\rangle\right|^{2}}{E_{n}^{0}-E_{r}^{0}}
$$

Sehingga persamaan untuk menentukan tingkat energi ke-n dapat dituliskan sebagai

$$
E_{n}=E_{n}^{(0)}+\lambda\left\langle n\left|H_{1}\right| n\right\rangle+\lambda^{2} \sum_{r \neq n} \frac{\left|\left\langle n\left|H_{1}\right| r\right\rangle\right|}{E_{n}^{0}-E_{r}^{0}}
$$

\section{Metodologi}

Penelitian ini dilakukan melalui tahapantahapan: studi pustaka, penentuan tingkat energi, dan analisis. Studi pustaka meliputi studi metode yang digunakan pada penelitian ini. Penentuan tingkat energi keadaan dasar dilakukan dengan menghitung tingkat energi osilator kuantum anharmonik menggunakan teori gangguan. Analisis dilakukan untuk mengetahui pengaruh suku gangguan terhadap perubahan tingkat energi.

\section{Hasil dan Diskusi}

Tingkat energi ke-n osilator kuantum anharmonik dengan suku gangguan $\lambda x^{m}$ dengan batas $m=4$ hingga koreksi energi orde kedua yang diperoleh menggunakan teori gangguan adalah sebagai berikut :

a. Suku gangguan $\lambda x$

$$
E_{n}=\left(n+\frac{1}{2}\right)-\lambda^{2} \frac{1}{2}
$$

b. Suku gangguan $\lambda x^{2}$

$$
E_{n}=\left(n+\frac{1}{2}\right)+\lambda(2 n+1)-\lambda^{2}(2 n+1)
$$

c. Suku gangguan $\lambda x^{3}$

$$
E_{n}=\left(n+\frac{1}{2}\right)-\lambda^{2} \frac{1}{8}\left(30 n^{2}+30 n+11\right)
$$

d. Suku gangguan $\lambda x^{4}$

$$
E_{n}=\left(n+\frac{1}{2}\right)+\lambda \frac{3}{4}\left(2 n^{2}+2 n+1\right)-\lambda^{2} \frac{1}{8}\left(34 n^{3}+51 n^{2}+59 n+21\right)
$$


Berikut ini merupakan gambar 1. yang merupakan perbandingan energi keadaan dasar osilator kuantum anharmonik untuk beberapa suku gangguan

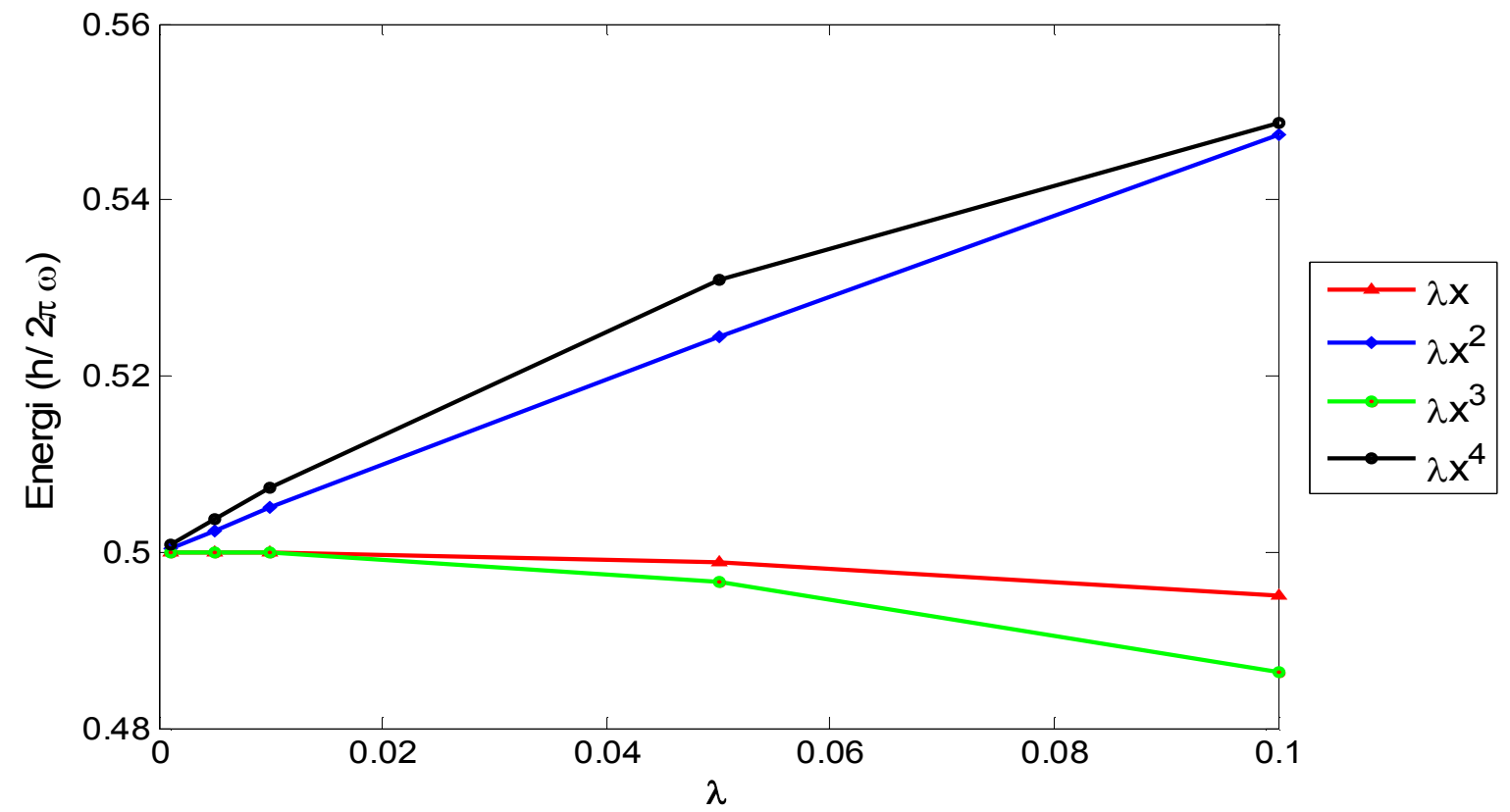

Gambar 1. Perbandingan energi keadaan dasar $\left(\mathrm{E}_{0}\right)$ osilator kuantum anharmonik untuk beberapa suku gangguan

Dari gambar terlihat untuk setiap suku gangguan berpangkat ganjil maka energi akan berkurang. Pada suku gangguan ini koreksi energi orde pertama sama dengan nol sehingga energi berkurang akibat koreksi energi orde kedua pada persamaan (11) dan (13) yang sebanding dengan kuadrat $\lambda$. Sedangkan untuk setiap suku gangguan berpangkat genap energi akan bertambah. Hal ini disebabkan karena koreksi energi orde pertama pada persamaan (12) dan (14) lebih dominan daripada koreksi energi orde kedua. Pertambahan energi ini sebanding dengan $\lambda$.

Berikut ini merupakan gambar 2. yang merupakan perbandingan energi tingkat pertama osilator kuantum anharmonik untuk beberapa suku gangguan

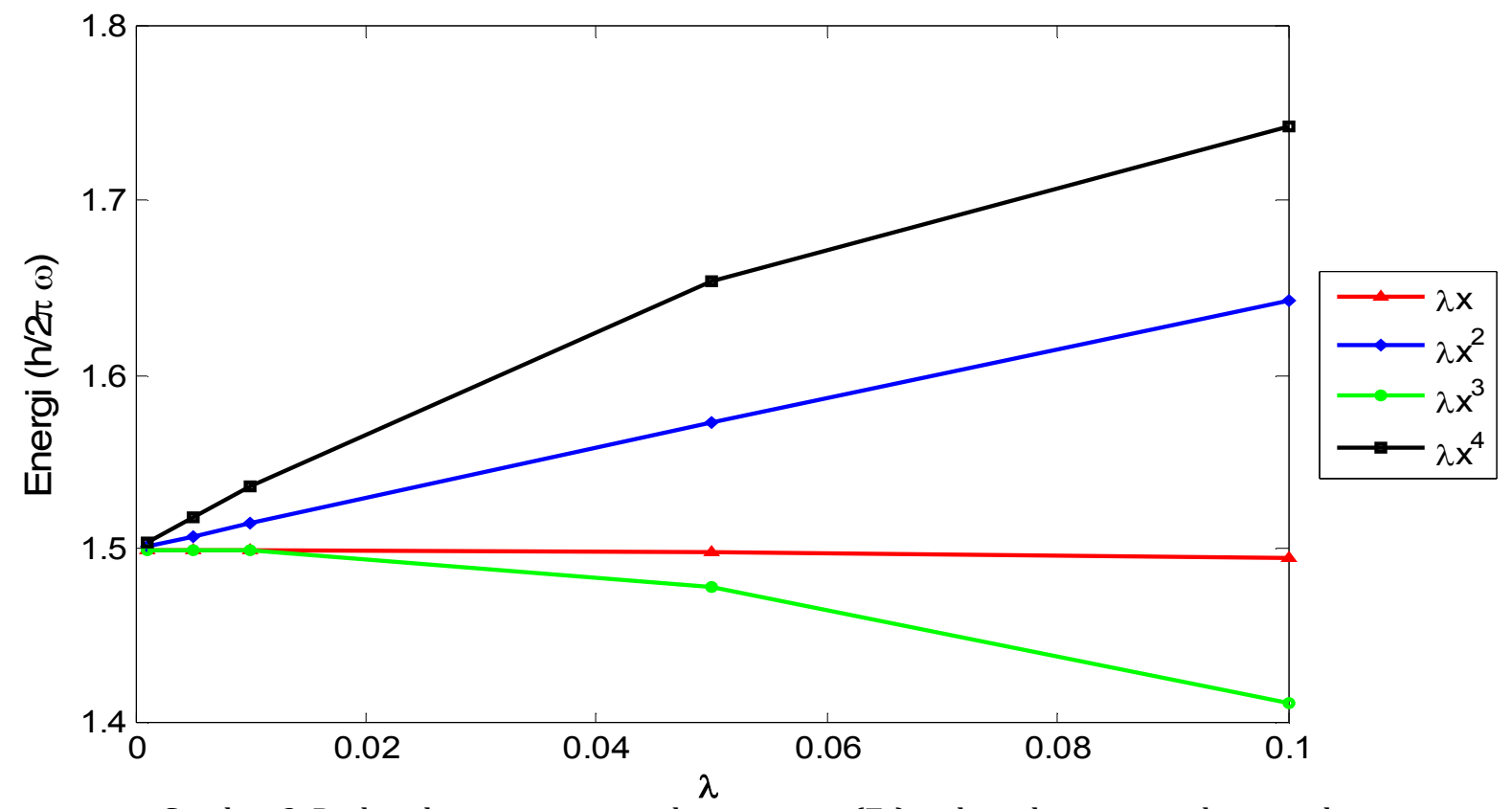

Gambar 2. Perbandingan energi tingkat pertama ( $\left.E_{1}\right)$ osilator kuantum anharmonik untuk beberapa suku gangguan 
Dari gambar terlihat perbandingan energi tingkat pertama $\left(\mathrm{E}_{1}\right)$ osilator kuantum anharmonik untuk beberapa suku gangguan memiliki pola yang sama dengan perbandingan energi keadaan dasar $\left(\mathrm{E}_{0}\right)$ osilator kuantum anharmonik untuk beberapa suku gangguan. Energi akan berkurang sebanding kuadrat $\lambda$ untuk setiap suku gangguan berpangkat ganjil dan bertambah sebanding $\lambda$ untuk setiap suku gangguan genap.

Meskipun memiliki pola yang sama, namun pada gambar 1 dan 2 terdapat perbedaan yaitu besar perubahan energi pada tiap tingkatan energi. Perubahan energi tingkat pertama lebih besar dari perubahan energi pada energi keadaan dasar. Hal ini disebabkan karena pada teori gangguan perubahan energi akibat energi koreksi akan sebanding dengan tingkatan energi. Selain itu perubahan energi pada tingkatan energi juga dipengaruhi oleh nilai $\lambda$ digunakan. Perubahan energi ini akan sebanding dengan $\lambda$ digunakan.

Pada penelitian ini selain osilator kuantum anharmonik dengan suku gangguan yang tunggal, teori gangguan juga digunakan untuk menyelesaikan osilator kuantum anharmonik dengan suku gangguan dalam bentuk polinomial. Tingkat energi ke-n osilator kuantum anharmonik dengan suku gangguan dalam bentuk polinomial dengan batas $\mathrm{m}=4$ hingga koreksi energi orde kedua yang diperoleh menggunakan teori gangguan dapat dituliskan sebagai

$$
E_{n}=\left(n+\frac{1}{2}\right)+\lambda \frac{1}{4}\left(6 n^{2}+10 n+3\right)-\lambda \frac{1}{8}\left(34 n^{3}+81 n^{2}+93 n+38\right)
$$

Berdasarkan persamaan (15) terlihat bahwa solusi tingkat energi ke-n osilator kuantum anharmonik dengan suku gangguan dalam bentuk polinomial merupakan penjumlahan koreksi energi suku gangguan yang tunggal $\left(\lambda x^{m}\right)$. Artinya, apabila gangguan diberikan pada suatu sistem satu per satu, maka jumlah dari gangguan tersebut akan sama apabila gangguan diberikan secara bersamaan pada sistem itu.

Berikut ini merupakan gambar 3. yang merupakan perbandingan tingkat-tingkat energi osilator kuantum anharmonik dengan gangguan dalam bentuk polinomial

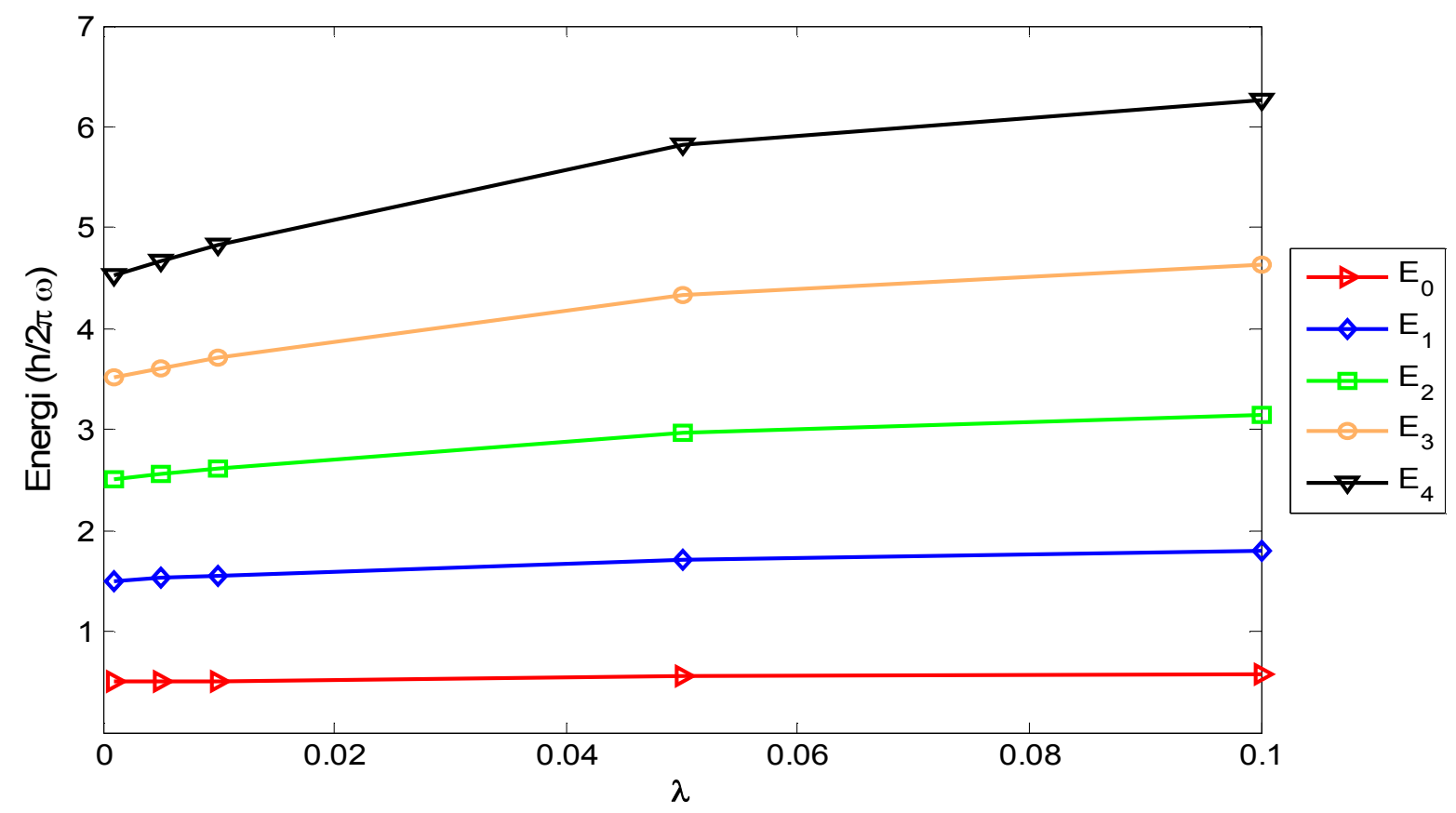

Gambar 2. Perbandingan tingkat-tingkat energi osilator kuantum anharmonik dengan gangguan dalam bentuk polinomial

Dari gambar terlihat bahwa perubahan energi pada tingkat-tingkat energi sebanding dengan tingkatan energi. Artinya semakin tinggi tingkatan energi maka semakin besar koreksi energi yang disebabkan oleh suku gangguan.
Selain itu perubahan energi juga sebanding dengan nilai $\lambda$ yang digunakan. Hal ini sama dengan suku gangguan yang tunggal. 


\section{Kesimpulan}

Perubahan tingkat-tingkat energi akibat suku gangguan dalam bentuk polinomial merupakan penjumlahan dari beberapa suku gangguan yang tunggal. Perubahan energi ini sebanding dengan tingkatan energi dan $\lambda$ yang digunakan.

\section{Pustaka}

Beiser, A., 1987, Konsep Fisika Modern, Edisi Ke4, Penerjemah: Liong, T. H. Erlangga, Jakarta.

Floyd, B.T.; Ludes, A.M.; Moua, C.; Ostle, A.A. and Varkony, O.B., 2011, Anharmonic Oscillator Potentials: Exact and Perturbation Result, Departmen of Physics, University of Nebraska at Ohama, Ohama, Nebraska 68182.

Griffiths, 1995, Introduction to Quantum Mechanics, Prentice Hall, Inc., Upper Saddle River, New Jersey.

Jafarpour, M. and Afshar, D., 2001, Calculation of energy eigenvalues for the quantum anharmonic oscillator with a polynomial potential, Journal of Physic A: Mathematical and General 35 (2002) 87-92.

Ohno, K., 2009, Teori Gangguan, http://www.chem-is-try.org/materi kimia/ kimia kuantum/metoda aproksimasi /teori gangguan.html, (12 Maret 2012).

Purwanto, A., 2006, Fisika Kuantum, Penerbit Gava Media, Yogyakarta.

Tjia, M.O., 1999, Mekanika kuantum, Penerbit ITB, Bandung.

Zen, F.P. dan Suroso, A., 2011, Catatan Kuliah Fisika Kuantum, Laboratorium Fisika teoritik, Institut Teknologi Bandung, Fakultas Matematika dan Ilmu Pengetahuan Alam, Bandung. 